\title{
Differential impact on acute kidney injury incidence between on- and off pump coronary artery bypass grafting in octogenarians
}

\author{
Rudolf Spunda ${ }^{\mathrm{a}}$, Martin Valek ${ }^{\mathrm{b}}$, Myroslav Salmay ${ }^{\mathrm{a}}$, Tomas Prskavec ${ }^{\mathrm{a}}$, Ondrej Pechac, Jaroslav Lindnera ${ }^{\mathrm{a}}$, Miroslav Spacek ${ }^{\mathrm{a}}$
}

\begin{abstract}
Introduction. Acute kidney injury (AKI) following surgical myocardial revascularization is associated with high mortality and morbidity. The aim of this study was to evaluate the risk of acute kidney injury in a population of very old patients following different surgical techniques.

Patients and Methods. A retrospective study of 310 consecutive patients aged 78 to 93 years, mean $80.5 \pm 2.2$, who underwent surgery at one cardiac surgery centre. Based on the surgical technique used the patients were divided into: Group I. CABG $(n=134)$ - surgical myocardial revascularization using extracorporeal circulation and arterial and venous grafts. Group II. OPCABG $(n=55)$ - surgical revascularization without extracorporeal circulation but using arterial and venous grafts. Group III. NOTOUCH $(n=121)$ - no handling with the ascending aorta was performed at all.

Results. A statistically insignificant renoprotective trend was found in patients who underwent surgery without extracorporeal circulation regardless of technique. Comparing groups II and III vs. group I, a significantly poorer renal functioning (median difference in creatinine was 10.0 (32.9) vs 17.5 (35.0), $P=0.05$ ) was shown for patients in group I. Conclusion. Surgical myocardial revascularization without extracorporeal circulation in very old patients is safe. The results of this study show a renoprotective trend.
\end{abstract}

Key words: acute kidney injury, coronary artery bypass grafting, octogenarians

Received: November 25, 2013; Accepted: April 24, 2014; Available online: May 30, 2014

http://dx.doi.org/10.5507/bp.2014.023

\author{
${ }^{a} 2^{\text {nd }}$ Department of Surgery - Department of Cardiovascular Surgery, $1^{\text {st }}$ Faculty of Medicine, Charles University in Prague and General \\ University Hospital in Prague, Czech Republic \\ ${ }^{b} 2^{\text {nd }}$ Department of Internal Medicine - Department of Cardiovascular Medicine, $1^{\text {st }}$ Faculty of Medicine, Charles University in Prague and \\ General University Hospital in Prague \\ Institute of Biophysics and Informatics, $1^{\text {st }}$ Faculty of Medicine, Charles University in Prague \\ Corresponding author: Miroslav Spacek, e-mail:mirekspacek@seznam.cz
}

\section{INTRODUCTION}

Acute kidney injury (AKI) following surgical myocardial revascularization is associated with high morbidity and mortality ${ }^{1-3}$. Complications occur in $1.4-19 \%$ of operated patients with a predicted mortality of between $7-38 \%\left(\right.$ ref. $\left.^{4}\right)$. According to the literature, the increased incidence of AKI is associated with the use of extracorporeal circulation (CPB) (ref. $\left.{ }^{5,6}\right)$. Impaired glomerular and tubular function is the cause $e^{4}$. The reason for this negative effect of $\mathrm{CPB}$ on the kidneys is the inflammatory reaction associated with the $\mathrm{CPB}$, non-pulsatile flow of the extracorporeal circulation, haemodilution, possible renal hypoperfusion, atheroembolization and others ${ }^{7}$. Surgery without extracorporeal circulation as well as avoiding handling the ascending aorta (no-touch aorta technique) and therefore preventing distal embolization of the atheromatous masses in the ascending aorta, is a technical prerequisite for minimizing post-operative AKI (ref. ${ }^{8,9}$ ). Maximum benefit can be expected, especially in octogenarian patients ${ }^{10,11}$. The purpose of this study was to evaluate the risk of acute kidney injury in an at risk population of very old patientsfollowing three surgical techniques: on-pump coronary artery bypass (CABG), off-pump coronary artery bypass (OPCABG) or no-touch off-pump coronary artery bypass (NOTOUCH). No as- sessment of this most risky group of elderly patients has been done to our knowledge.

\section{PATIENTS AND METHODS}

\section{Patient populations}

Retrospective study to monitor patients who had undergone surgery at one cardiac surgery centre. The sample included 310 consecutive patients, aged 78-93 years, mean age $80.5 \pm 2.2$, median 80.0 years. These had undergone surgical myocardial revascularization from 2003 till the end of 2009. The patients were divided into three subgroups according to the type of surgery and level of handling the ascending aorta.

\section{Surgical technique}

In the I. CABG group $(n=134)$ patients underwent surgical myocardial revascularization using extracorporeal circulation and arterial and venous grafts.

In the II. OPCABG group $(n=55)$, patients underwent surgical revascularization without extracorporeal circulation and with the use of the arterial and venous grafts. In contrast to the $\mathrm{CABG}$ group the ascending aorta was handled only when central anastomoses of the venous bypasses were sewed on. 
In the last group III called NOTOUCH $(n=121)$ no handling with the ascending aorta was performed at all. These patients were operated without extracorporeal circulation and only arterial grafts were used for the bypasses - left a. thoracica interna (LIMA), right a. thoracica interna (RIMA) and a. radialis (RA). The LIMA and RIMA were used in situ with a separation from a. subclavia left in place or as composite T and Y grafts. The RA was taken from the non-dominant upper extremity with negative Allen test and it was used solely as a composite T (Y) graft.

\section{Assessment of renal parameters}

Glomerular filtration rate (GFR) was calculated in all patients using the formula adopted from the Modification of Diet in Renal Disease study (MDRD) (ref. ${ }^{12}$ ). The chronic kidney disease (CKD) classification was used to evaluate the stage of pre-operative renal function impairment ${ }^{13}$. All patients who were in stage 5 CKD (GFR < $15 \mathrm{~mL} / \mathrm{min}$ or dialysis) were excluded from the study.

The post-operative AKI and its stages were defined in accordance with the Acute Kidney Injury Network criteria
(AKIN) (ref. $\left.{ }^{14}\right)$. The AKI was defined as an increase of serum creatinine by $\geq 50 \%$ or by $>26 \mu \mathrm{mol} / \mathrm{L}$ compared to the pre-operative value (during $48 \mathrm{~h}$ ). The severity of AKI was classified as stage 1 (increase in creatinine by $\geq 50 \%$ or by $>26 \mu \mathrm{mol} / \mathrm{L}$ ), stage 2 (increase in creatinine by 101$200 \%$ ), and stage 3 (increase in creatinine by $>200 \%$ or as a pre-operative creatinine $\geq 354 \mu \mathrm{mol} / \mathrm{L}$ and increase in creatinine by $44 \mu \mathrm{mol}$ or renal replacement therapy). Because the stages 2 and 3 of AKI were achieved in few patients, these groups were not statistically evaluated separately.

A post-operative worsening of renal functions was also seen using the difference in values of serum creatinine concentration before the surgery and maximum value after the surgery during patient's stay at the Intensive Care Unit (ICU).

\section{Statistical evaluation}

All continuous variables were initially tested for normality using Kolmogorov-Smirnov test. Since almost all of these variables were non-normally distributed, the nonparametric Kruskal-Wallis test was used to compare dif-

Table 1. Characteristics of the group of patients $(n=310)$.

\begin{tabular}{|c|c|c|c|c|}
\hline & $\begin{array}{c}\text { No touch } \\
\text { Off-pump CAB }\end{array}$ & $\begin{array}{l}\text { Off-pump } \\
\text { CAB }\end{array}$ & $\begin{array}{l}\text { On-pump } \\
\text { CAB }\end{array}$ & $P$ \\
\hline Patients & 121 & 55 & 134 & \\
\hline \multirow[t]{2}{*}{ Age (years) } & $80.8 \pm 2.3$ & $80.8 \pm 2.8$ & $80.1 \pm 1.9$ & 0.11 \\
\hline & $80.0(4)$ & $78(3.0)$ & $80.0(2.0)$ & \\
\hline Male gender $(\%)$ & 65.3 & 56.4 & 73.7 & 0.06 \\
\hline \multirow[t]{2}{*}{ EuroSCORE Additive } & $8.0 \pm 2.7$ & $7.9 \pm 2.3$ & $8.0 \pm 3.1$ & 0.66 \\
\hline & $8.0(3.5)$ & $7.5(3.5)$ & $7.0(3.0)$ & \\
\hline \multirow[t]{2}{*}{ EuroSCORE Logistic } & $14.4 \pm 12.8$ & $12.7 \pm 7.9$ & $15.5 \pm 15.5$ & 0.81 \\
\hline & $10.0(12.1)$ & $10.0(12.3)$ & $9.6(13.6)$ & \\
\hline \multirow[t]{2}{*}{ Left ventricular ejection fraction (\%) } & $52 \pm 14$ & $51 \pm 12$ & $50 \pm 13$ & 0.52 \\
\hline & $55(23)$ & $52(20)$ & $50(20)$ & \\
\hline Previous myocardial infarction (\%) & 61.9 & 69.8 & $50.0 *$ & 0.03 \\
\hline Diabetes mellitus (\%) & 41.8 & 39.6 & 45.4 & 0.74 \\
\hline Peripheral artery disease $(\%)$ & 21.6 & 24.6 & 16.9 & 0.45 \\
\hline \multirow[t]{2}{*}{ Serum creatinine preoperatively $(\mu \mathrm{mol} / \mathrm{L})$} & $105 \pm 32$ & $108 \pm 33$ & $113 \pm 35$ & 0.19 \\
\hline & $100(34)$ & $100(42)$ & $106(41)$ & \\
\hline \multirow{2}{*}{$\begin{array}{l}\text { Estimated glomerular filtration rate } \\
\text { preoperatively }\left(\mathrm{mL} / \mathrm{s} / 1.73 \mathrm{~m}^{2}\right)\end{array}$} & $0,85 \pm 0.26$ & $0.82 \pm 0.25$ & $0.82 \pm 0.24$ & 0.40 \\
\hline & $0.86(0.31)$ & $0.84(0.40)$ & $0.82(0.33)$ & \\
\hline \multirow[t]{2}{*}{ Intubation time $(\min )$} & $24.7 \pm 68.7$ & $41.9 \pm 181.4$ & $22.4 \pm 51.0$ & 0.11 \\
\hline & $8.0(7.5)$ & $9.0(6.3)$ & $10.0(8.0)$ & \\
\hline \multirow[t]{2}{*}{ Extracorporal circulation time (min) } & 0 & 0 & $92 \pm 44^{*}$ & $<0.001$ \\
\hline & & & $87(35)$ & \\
\hline \multirow[t]{2}{*}{ Aortic cross clamp time (min) } & 0 & 0 & $45 \pm 18^{*}$ & $<0.001$ \\
\hline & & & $43(18)$ & \\
\hline \multirow[t]{2}{*}{ Lenght of stay on intensive care unit (h) } & $129 \pm 101$ & $146 \pm 225$ & $124 \pm 136$ & 0.78 \\
\hline & $96(n=101)$ & $95(n=114)$ & $92(\mathrm{n}=77)$ & \\
\hline \multirow[t]{2}{*}{ Distal anastomoses $(\mathrm{N})$} & $2.3 \pm 1.0$ & $2.6 \pm 0.7$ & $3.5 \pm 1.0^{*}$ & $<0.001$ \\
\hline & $2(\mathrm{n}=1.0)$ & $3(n=1)$ & $3(n=1)$ & \\
\hline \multirow[t]{2}{*}{ Mammary artery $(\mathrm{N})$} & $1.6 \pm 0.7$ & $1.1 \pm 0.4^{*}$ & $1.0 \pm 0.6^{*}$ & $<0.001$ \\
\hline & $1(\mathrm{n}=1.0)$ & $1(\mathrm{n}=0)$ & $1(\mathrm{n}=0)$ & \\
\hline \multirow[t]{2}{*}{ Radial artery $(\mathrm{N})$} & $0.8 \pm 0.9$ & $0.02 \pm 0.13^{*}$ & $0.1 \pm 0.5^{*}$ & $<0.001$ \\
\hline & $1(\mathrm{n}=1)$ & $0(\mathrm{n}=0)$ & $0(\mathrm{n}=0)$ & \\
\hline \multirow[t]{2}{*}{ Vein $(\mathrm{N})$} & 0 & $1.5 \pm 0.6^{*}$ & $2.4(1.0)^{*}$ & $<0.001$ \\
\hline & & $1(n=1)$ & $2(n=1)$ & \\
\hline
\end{tabular}


ferences between the groups. The one-way ANOVA with Fisher LSD post-hoc tests was applied for the remaining normal variables. In the case of categorical variables, the chi-square test of independence including an analysis of standardized adjusted residuals was carried out to assess differences between the groups. Subsequently, the Wilcoxon test for paired samples was used to compare changes between the pre-test and post-test values. The differences were considered as significant when $P<0.05$. Results are expressed as means \pm standard deviation and as median and inter-quartile range in parenthesis. The data were processed using the statistical software SPSS (version 17.0). The graphs were constructed using the Statistica software (version 9.0).

\section{Patients characteristics}

Characteristics of the group are summarized in Table 1. There was no significant difference in renal functions before the surgery in the single groups expressed both by serum creatinine level or calculation of GFR using the MDRD formula. The patients in the single groups were not significantly different in age, gender ratio, EuroSCORE (ref. ${ }^{15}$ ), pre-operative ejection fraction, diabetes mellitus or peripheral artery disease. However, the patients in the CABG group had a lower rate of myocardial infarction in their medical history $(P=0.03)$. The CABG patients had a higher number of distal anastomoses compared with both off-pump groups $(P<0.001)$.

Group I. CABG - in this group the left a. thoracica interna (LIMA) was used in $113(84.3 \%)$ patients, vena saphena magna (VSM) in $128(95.5 \%)$ patients and a. radialis (RA) in $8(5.9 \%)$ patients. In this group we saw on average 3.5 distal anastomoses. Duration of EC on average was $92 \mathrm{~min}$ and the duration of transversal clamping of the aorta was on average $44 \mathrm{~min}$.

Group II. OPCABG - LIMA was used in 53 cases $(96.4 \%)$, VSM in $55(100 \%)$ patients. RA was used in $1(1.8 \%)$ patient. On average we performed 2.6 distal anastomoses.
Group III. NOTOUCH - These patients underwent surgery without extracorporeal circulation and only arterial grafts were used for the bypasses - LIMA (120 (99.2\%)), RIMA (26 (21.5\%)) and RA (63 (52\%)). LIMA and RIMA were used in situ with the branching from a. subclavia left in place or as composite $\mathrm{T}$ and $\mathrm{Y}$ grafts. RA was taken from the non-dominant limb with negative Allen test and it was used solely as a composite T (Y) graft. On average we performed 2.3 distal anastomoses. This group also includedpatients (21 patients) who underwent MIDCABG (mini-invasive direct coronary artery bypass grafting).

The results are reported as relative frequency, or as the means with standard deviations and medians with quartiles. *means statistically significant difference.

\section{RESULTS}

The results of renal functions are summarized in Table 2.

The results are expressed as numbers of patients and relative frequency, or as the means with standard deviations and medians with quartiles. ${ }^{*}$ means statistically significant difference.

In the whole group, a worsening of renal functions was assessed using the serum creatinine level $(P<0.001)$. As well, within all the subgroups (CABG, OPCABG, NOTOUCH) the serum creatinine levels were statistically significantly increased $(P<0.001, P=0.003, P<0.001)$. However, comparison of the intensity of worsening of creatinine between the groups was not significant. A slight trend can be seen, where the CABG group deteriorated more than the OPCABG and NOTOUCH groups $(P=0.12$, Fig 1). The maximum creatinine value after the surgery was not statistically significantly different between the groups but a slight trend can be seen as well where the $\mathrm{CAB}$ patients had higher values compared to the other groups $(P=0.10)$. When comparing both off-pump groups

Table 2. Renal data in the single groups. The results are presented as the numbers of patients and relative frequency, or as the means with standard deviations and medians with quartiles.

\begin{tabular}{|c|c|c|c|c|}
\hline & $\begin{array}{c}\text { No touch } \\
\text { Off-pump CAB }\end{array}$ & Off-pump CAB & On-pump CAB & $P$ \\
\hline Acute kidney injury, n (\%) & $38(31.4)$ & $16(29.0)$ & $56(41.8)^{*}$ & $<0.05$ \\
\hline Stage 1, n (\%) & $34(28.1)$ & $13(23.6)$ & $50(37.3)^{*}$ & $<0.05$ \\
\hline Stage $2, \mathrm{n}(\%)$ & $2(1.7)$ & $1(1.8)$ & $2(1.5)$ & \\
\hline Stage 3 , n (\%) & $2(1.7)$ & $2(3.6)$ & $4(3.0)$ & \\
\hline Serum creatinine preoperatively $(\mu \mathrm{mol} / \mathrm{L})$ & $\begin{array}{l}105 \pm 32 \\
100(34)\end{array}$ & $\begin{array}{l}108 \pm 33 \\
100(42)\end{array}$ & $\begin{array}{l}113 \pm 35 \\
106(41)\end{array}$ & 0.19 \\
\hline Maximum serum creatinine postoperatively ( $\mu \mathrm{mol} / \mathrm{L})$ & $\begin{array}{l}129 \pm 66 \\
111(60)\end{array}$ & $\begin{array}{l}127 \pm 59 \\
106(43)\end{array}$ & $\begin{array}{l}138 \pm 60 \\
121(70)\end{array}$ & 0.10 \\
\hline Serum creatinine difference $(\mu \mathrm{mol} / \mathrm{L})$ & $\begin{array}{l}23.1 \pm 55.2 \\
10.0(31.8)\end{array}$ & $\begin{array}{l}19.0 \pm 47.6 \\
10.0(40.0)\end{array}$ & $\begin{array}{c}25.8 \pm 59.9 \\
17.5(37)\end{array}$ & 0.12 \\
\hline Renal replacement therapy postoperatively, N (\%) & $2(1.7)$ & $2(3.6)$ & $4(3.0)$ & \\
\hline
\end{tabular}


together versus the on-pump group, renal functioning was poorer in on-pump patients, which was statistically significant (median of creatinine difference 10.0 (32.9) vs 17.5 (35.0), $P=0.05)$.

When comparing the occurrence of AKI according to the AKIN criteria the CABG patients had a significantly higher risk of AKI compared to the OPCABG or NOTOUCH patients. There was no statistically significant difference between the OPCABG or NOTOUCH group regarding the AKI (Fig. 2).

The same dependence was seen in the stage of AKIN 1. A significant renal function impairment after the surgery was relatively less common. $4.2 \%$ patients of patients achieved stage 2 and 3 and only $2.5 \%$ of patients achieved stage 3 out of the whole group. The AKIN stages 2 and 3 were not statistically evaluated due to small numbers of patients in the groups. In total 5 patients achieved stage 2 and 8 patients achieved stage 3. All patients of the AKIN stage 3 had to be dialyzed. Except for one patient, all patients in the AKIN stage 3 had chronic kidney disease before the surgery - three patients had the CKD stage 3 and four patients stage 4 .

\section{DISCUSSION}

Acute kidney injury following surgical myocardial revascularization is a relatively common and very serious post-operative complication ${ }^{3,16,17}$. In patients from 80 to 89 years of age it is associated with higher mortality and it significantly prolongs hospitalization at the ICU (ref. ${ }^{11,18}$ ). The mechanism includes impairment of glomerular filtration and tubular function due to system inflammatory response associated with the use of extracorporeal circulation, non-pulsatile flow of the extracorporeal circulation, haemodilution, possible hypoperfusion of the kidneys, atheroembolization and other causes ${ }^{5,6}$. The systemic inflammatory response develops also following surgery without extracorporeal circulation in contrast to the procedures with $\mathrm{EC}$, however the reaction is not so serious and the final effect on the renal functions is less serious ${ }^{19,20}$. Haemodilution and non-pulsatile flow are specific characteristics of the extracorporeal circulation and they do not occur during the OPCABG procedures. Hypotension associated with renal hypoperfusion is more probable during the OPCABG revascularization procedure, especially in stabilization of the coronary arteries of the lateral and inferior wall of the left ventricle ${ }^{21}$. Atheroembolization from atherosclerotic plaques in the ascending aorta is another possible mechanism of renal function impairment. Embolism occurs most commonly during handling the ascending aorta when the arterial cannula is inserted in the extracorporeal circulation and when the transversial or mural clamp is placed on the ascending aorta ${ }^{22}$. The mural clamp is used during sewing the central anastomoses of venous bypasses to the ascending aorta and the risk of embolism is therefore also present in the case of OPCABG revascularization using the venous grafts. During the no-touch technique (NOTOUCH) we eliminate handling of the ascending

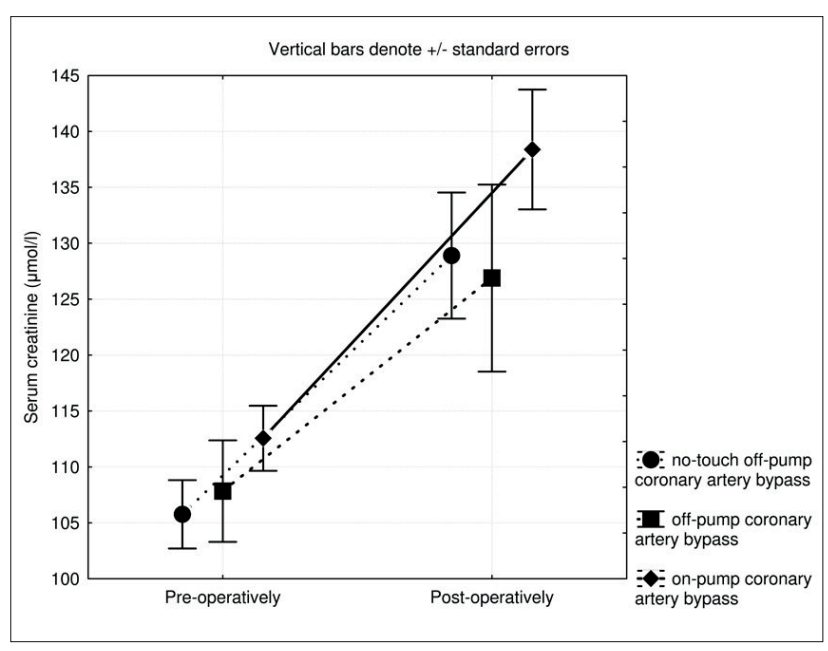

Fig. 1. Maximum creatinine value postoperatively.

Pre- and post-operative serum creatinine levels difference in $\mathrm{CABG}$, OPCABG and NOTOUCH group. A slight trend can be seen as well where the $\mathrm{CABG}$ patients had higher values compared to the other groups $(P=0.12)$

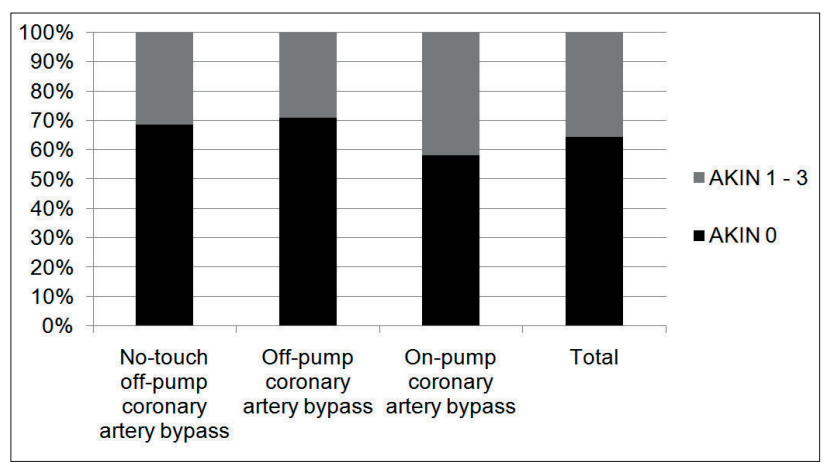

Fig. 2. Occurrence of AKI.

CABG group had a significantly higher risk of AKI compared to the OPCABG and NOTOUCH group

aorta, the surgery is performed without extracorporeal circulation and only arterial grafts are used in situ or as composite $^{9}$. For this reason, the risk of embolization of the atherosclerotic plaques from the ascending aorta is reduced to a minimum. However, if the surgical technique is not well-done, the risk of hypotension persists with stabilization of the coronary arteries. Based on this, it can be assumed that the surgery without the extracorporeal circulation (OPCABG and NOTOUCH) will benefit by lower incidence of renal failure post-operatively, especially in octogenarians.

According to our knowledge, this study is the first which is aimed at the risk of AKI in relation to the use of extracorporeal circulation in a selected, at risk population of very old patients.

A renoprotective effect can be seen in the study results in favour of patients not undergoing extracorporeal circulation compared to its use. However, the effect of the no-touch technique vs off-pump technique with handling the aorta ascendent on AKI was not found and both offpump groups had the same risk of AKI. Implementation of the extracorporeal circulation appears to be the main 
risk factor. The mechanism of renal function impairment by embolization of atheromatic masses during handling the ascending aorta was not found to be important in our study.

Early post-operative renal impairment was mostly mild - most in patients in the AKIN 1 group. Treatment using the RRT in the early post-operative period compromises especially patients with significant renal insufficiency post-operatively.

However, the study is limited by the fact that only a small number of patients had significant kidney impairment of stage 2 and especially stage 3 . This precluded evaluating whether the patients in the OPCABG and NOTOUCH groups had a smaller risk of the clinically most significant forms of AKI - including the need for RRT. In contrast to Di Mauro et al. ${ }^{4}$, we do not think that choice of surgery using extracorporeal circulation plays a negative role only in patients with normal preoperative renal parameters. We can see the advantages of surgery without extracorporeal circulation in patients with renal impairment pre-operatively. This observation is principally in accordance with the conclusions of extensive meta-analysis of randomized and observational studies aimed at this topic published by Nigwekarn et al. ${ }^{23}$ despite the methodologically insufficiently defined AKI.

It must be emphasized that evaluation of the renal parameters is only a small but significant part of evaluating the results of surgical revascularization in very old patients. Another significant group of monitored parameters is neurological outcome that is significantly better ${ }^{24}$, based on some studies in patients operated using the no-touch aorta technique, on condition that the surgical technique is perfectly managed, i.e. comparable revascularization parameters ${ }^{25}$, such as its completeness (comparable number of peripheral anastomoses) and pre-operative haemodynamical stability, especially during revascularization of the lateral and inferior wall of the ventricle.

\section{CONCLUSION}

With the development of medicine and increased mean age of the population, the number of very old patients indicated for surgical myocardial revascularization is increasing. Cardiac surgery in these patients is associated with a higher risk of morbidity and mortality including renal failure. To reduce thisrisk and based on our results, selection of less invasive procedures, such as off-pump myocardial revascularization, or with no-touch aorta technique is recommended.

To confirm the advantages of a method, multicenter studies are needed. The long-term outcome of renal functions in patients in relation to surgical technique used would be a very important factor as patients whose renal functions failed to recover and were included in chronic dialyzation programs have markedly higher morbidity and mortality and significantly worse quality of life.

\section{ACKNOWLEDGEMENT}

Author contributions: RS, MV, MyS, TP, OP, JL, MiS: conception and design; RS, MV, MyS, TP, OP, JL, MiS: data analysis and interpretation; RS, MV, MyS, TP, MiS: data collection.

Conflict of interest statement: None declared.

\section{REFERENCES}

1. Shroyer ALW, Coombs LP, Peterson ED. The Society of Thoracic Surgeons: 30-day operative mortality and morbidity risk models. Ann Thorac Surg 2003;75:1856-64.

2. Chertow G, Mazarus J, Christiansen C. Preoperative renal risk stratification. Circulation 1997;95:878-84.

3. Settergren G, Ohqvist $G$. Renal dysfunction during cardiac surgery. Curr Opin Anesthesiol 1994;7:59-64.

4. Di Mauro $M$, Gagliardi $M$, laco AL, Contini M, Bivona A, Bosco $P$, Gallina S, Calafiore AM. Does off pump coronary Sumery reduce postoperative acute renal silure? The importace of preoperative renal fiction. Ann Thorac Surg 2007:84:1496-502.

5. Abel RM, Buckley MJ, Austen WG. Etiology, incidence and prognosis of renal failure following cardiac operations: results of a prospective analysis of 500 consecutive patients. J Thorac Cardiovasc Surg 1976;71:323-33.

6. Utley JR. Renal function and fluid balance with cardiopulmonary bypass, in Gravlee GP, Davis RF, Utley JR (eds): Cardiopulmonary Bypass: Principles and Practice. Baltimore, Williams \& Wilkins 1993:488.

7. Andersson LG, Ekroth R, Bratteby LE. Acute renal silure after coronary Sumery: a study of incidence and risk factors in 2009 consecutive patiens. Thorac Cardiovasc Surg 1993:41:237-41.

8. Puskas J, Cheng D, Knight J. Off-pump versus conventional coronary artery bypass grafting: A meta-analysis and consensus statement from the 2004 ISMICS consensus conference. Innovations 2005;1:3.

9. Navia D, Vrancic M, Vaccarino G. Total arterial off-pump coronary revascularization using bilateral internal thoracic arteries in triple vessel disease: surgical technique and clinical outcome. Ann Thorac Surg 2008;86:524-31.

10. Akins CW, Daggett WM, Vlahakes GJ. Cardiac operations in patients aged 80 years old and older. Ann Thorac Surg 1997;64:606-14.

11. Peterson ED, Cowper PA, Jollis JG. Outcomes in coronary artery bypass graft surgery in 24,461 patients aged 80 years or older. Circulation 1995;92:85-91.

12. Levey AS, Coresh J, Greene T. Chronic Kidney Disease Epidemiology Collaboration: Using standardized serum creatinine values in the modification of diet in renal disease study equation for estimating glomerular filtration rate. Ann Intern Med 2006;145:247-54.

13. National Kidney Foundation. K/DOQI clinical practice guidelines for chronic kidney disease: evaluation, classification, and stratification. Am J Kidney Dis 2002;39(Suppl 1):S1-266.

14. Mehta RL, Kellum JA, Shah SV. Acute Kidney Injury Network: report of an initiative to improve outcomes in acute kidney injury. Crit Care 2007;11:R31.

15. Roques F, Nashef SA, Michel P. Risk factors and outcome in European cardiac surgery: analysis of the EuroSCORE multinational databasis of 19030 patients. Eur J Cardiothorac Surg 1999;15:816-23.

16. Zanardo $G$. Acute renal failure in the patient undergoing cardiac operation: prevalence, mortality rate, and main risk factors. JThorac Cardiovasc Surg 1994;107:1489-95.

17. Andersson LG, Ekroth R, Bratteby LE. Acute renal failure after coronary surgery-a study of incidence and risk factors in 2009 consecutive patients. Thorac Cardiovasc Surg 1993;41:237-41.

18. Williams DB, Carrillo RG, Traad EA. Determinants of operative mortality in octogenarians undergoing coronary bypass. Ann Thorac Surg 1995;60:1038-43.

19. Biglioli P, Cannata A, Alamanni F. Biological effects of off-pump versus on-pump coronary artery surgery: focus on inflammation, haemostasis and oxidative stress. Eur J Cardiothorac Surg 200;24:260-9.

20. Wehlin L, Vedin J, Vaage J. Activation of complement and leukocyte receptors during on- and off pump coronary artery bypass surgery. Eur J Cardiothorac Surg 2004;25:35-42. 
21. Tang AT, Knott J, Nanson J. A prospective randomised study to evaluate the renoprotective action of beating heart coronary surgery in low risk patients. Eur J Cardiothoracic Surg 2002;22:118 -23.

22. Doty JR, Wilentz RE, Salazar JD. Atheroembolism in cardiac surgery. Ann Thorac Sur 2003;75:1221-6.

23. Nigwekar S, Kandula P, Hix J. Off pump coronary artery bypass Sumery and acute kidney injury: A meta analysis of randomized and observational studies. Am J Kidney Dis 2009:54:413-23.
24. Misfeld M, Brereton RJ, Sweetman EA. J Thorac CardioNeurologic complications after off-pump coronary artery bypass grafting with and without aortic manipulation: Meta-analysis of 11,398 cases from 8 studies. Vasc Surg 2011;142:e11-17.

25. Shroyer AL, Grover FL, Hattler B. On pump versus off pump coronary artery bypass Sumery N Engl J Med 2009:361:1827-37. 